\title{
O poeta, o louco e a criança: companheiros de brincriação e enquadramentos táticos de sobrevivência
}

\section{The poet, the madman, and the child: partners in the game of language} and strategic framings in order to survive

Breno Fernandes 1

Doutorando do Programa de Pós-Graduação em Literatura \& Cultura da Universidade Federal Bahia, cuja pesquisa trata do desmantelamento do discurso de nação identificado em romances de guerra civil contemporâneos.

-0002-2674-28

E-mil:
RESUMO: Este artigo propõe uma leitura de Terra sonâmbula, romance de Mia Couto sobre a Guerra Civil de Moçambique (1977-1992), motivada pela justaposição que, em As palavras e as coisas, Michel Foucault faz com o poeta e o louco, ao analisar o modo de usar a linguagem que ambos compartilham e, a despeito disso, as distinções que são feitas entre eles em relação a esse uso. A amalgamação aqui realizada se deve a que o poeta e o louco são personagens marcantes na trama de Terra sonâmbula, e, junto a eles, aparece também a criança, como outro sujeito que desloca a relação da linguagem com a verdade e que trata aquela como um jogo, como matéria de brincriação, para usar um neologismo cunhado pelo próprio Mia Couto. Ao mesmo tempo, a leitura do romance apresentada oferece pistas de que esses papéis sociais ou enquadramentos, de poeta, de louco e de criança, não raro tomados como construtos desviantes ou precários, podem se revelar, em contexto de guerra e mesmo fora dele, uma astuta tática de sobrevivência.

Palavras-chave: Enquadramento; Guerra; Mia Couto; Signo Linguístico; Sobrevivência.

ABSTRACT: This paper proposes reading Terra sonâmbula, Mia Couto's novel about the Mozambique Civil War (1977-1992), in connection to Michel Foucault's parallel between the poet and the madman, presented in The order of things. In this book, Foucault analyses how the poet and the madman similarly play with the language, regardless of how distinctively they have been judged for their common use of the language. This connection between Couto and Foucault is justified by the presence of the poet and the madman in Terra sonâmbula. The child also appears in the novel as a third type of subject who breaks the link between the language and the truth by playing with the language. After associating the poet with the madman, and with the child, it is suggested that these social roles or framings, commonly taken as deviant or precarious, whether in a war context or in others, may be a clever survival tactic.

Keywords: Framing; War; Mia Couto; Linguistic Sign; Survival. 


\section{Ponto de encontro}

e, como nos conta Deleuze (1997), a arte "é feita de trajetos e devires, $\checkmark$ por isso traz mapas" (DELEUZE, 1997, p. 78), este artigo trata de rotas de fuga para quem deseja escapar dos horrores da guerra quando o deslocamento geográfico não parece ser uma opção eficaz. O caminho a se tomar é o da língua, e a única maneira de encontrá-lo é sem bússola, com disposição para se perder. Parece brincadeira, e é mesmo. Mas é brincadeira de criar - brincriação, para usar esse tesouro vocabular achado por Mia Couto (2015). Um jogo de construir com palavras uma barricada que pode até não deter balas, mas que blinda a sanidade, ainda que, para isso, e por paradoxal que pareça, talvez seja necessário enlouquecer.

Sigamos Butler (2015) e chamemos essa barricada de enquadramento. Ao apresentar sua compreensão do conceito, a filósofa toma as ações de emoldurar quadros e de ser enquadrado perante a lei para nos explicar que o enquadramento é "[u]ma determinada maneira de organizar e apresentar" (BUTLER, 2015, p. 23), mas que sempre deixa algo de fora, tornando assim "o próprio sentido de dentro possível, reconhecível" (BUTLER, 2015, p. 24) - seja esse 'dentro' a moldura que nos dá a noção de limite da cena do quadro ou a letra da lei que enquadra alguns sujeitos e outros não. Em síntese, vislumbrar o 'fora' é imprescindível para se enxergar o 'dentro'. Ou, nas palavras de Butler (2015), "[o] enquadramento [...] busca conter, transmitir e determinar o que é visto" (BUTLER, 2015, p. 25), mas "[a] moldura nunca determinou realmente, de forma precisa o que vemos, pensamos, reconhecemos e apreendemos" (BUTLER, 2015, p. 24).

Graças a essa brecha, temos alguma agência no jogo de identidades, que é também o jogo de enquadramentos a que estamos sujeitos. É essa a rota de fuga da qual se valem alguns personagens de Terra sonâmbula, romance de Mia Couto, de 1992, cuja trama se passa no período da Guerra Civil de
Moçambique (1977-1992). ${ }^{1}$ Com ajuda das reflexões de Foucault (1999) sobre os enquadramentos que são dados ao poeta e ao louco, percebeu-se que a presença de ambos em Terra sonâmbula não é por acaso: são eles enquadramentos táticos, utilizados como estratégia de sobrevivência ao caos da guerra civil, como melhor será explicado nos Trechos A e B desse mapeamento. Já no Trecho $\mathrm{C}$, explora-se uma terceira rota de fuga, um terceiro enquadramento que se coaduna harmonicamente com as reflexões de Foucault (1999) acerca do poeta e do louco, como o demonstra Terra sonâmbula. Trata-se da criança.

Juntos, o poeta, o louco e a criança compartilham o prazer por brincriar com a linguagem e destarte acabam gerando tensões em relação ao que tomamos como natural ou verdadeiro. Em outras palavras, seu jogo nos faz vislumbrar o 'fora' que torna o 'dentro' reconhecível. Ao mesmo tempo, aprendemos com Terra sonâmbula, com os personagens que tomam - ou que lhes têm imputados - tais enquadramentos, que às vezes o lugar que consideramos o mais precário pode ser onde encontraremos a guarida mais eficaz. Em meio a uma população assolada pela carnificina da guerra, o poeta, a louca e as crianças do romance de Mia Couto (2015) são os únicos que, em certa medida, conseguem manter-se afastados dela.

Façamo-lhes companhia em sua fuga.

${ }^{1}$ A Guerra Civil Moçambicana seguiu-se à Guerra de Independência contra Portugal, que durou de 1964 a 1975, impulsionada pela Frente de Libertação de Moçambique (Frelimo), sob o comando de Eduardo Mondlane (1920-1969) e mais tarde de Samora Machel (1933-1986). Com a vitória dos moçambicanos, a transformação da Frelimo em partido político de orientação marxista-leninista e a aproximação entre o governo do país recém-independente e o bloco comunista da Guerra Fria, então em curso, entre o governo do país recém-independente e o bloco comunista da Guerra Fria, então em curso, os vizinhos capitalistas de Moçambique, Zimbábue e África do Sul, incentivaram a formação de uma coalizão de descontentes e de dissidentes da Frelimo, batizada de Resistência Nacional Moçambicana (Renamo), de caráter anticomunista. O conflito só terminou quando foram assinados acordos de paz que, entre outros arranjos, instituíram na prática o multipartidarismo no regime político do país. Para
mais detalhes, cf. ARAGÃO, 2017, p. 57-74. 


\section{Trecho A: literatura como sobrevivência}

"A terra é imensa, a guerra é maior ainda" (COUTO, 2015, p. 190). É assim que Farida, uma personagem de Terra sonâmbula, manifesta a desesperança de um dia vir a encontrar o filho em um país onde o conflito armado já leva anos e não parece prestes a acabar. A guerra afinal devasta tudo: a terra e o que nela há. Esfacela em segundos o que o homem empenhou anos para construir, o que a natureza levou eras para criar. Está lá, nas primeiras linhas do romance: "Naquele lugar, a guerra tinha morto a estrada. Pelos caminhos só as hienas se arrastavam, focinhando entre cinzas e poeiras. A paisagem se mestiçara de tristezas nunca vistas" (COUTO, 2015, p. 9). Nesse cenário, os reencontros se tornam difíceis ou quase impossíveis, mesmo aqueles que a morte ainda não impediu para sempre de acontecer.

Mas não é só o poder devastador que faz a guerra maior do que a terra. É também uma questão de disseminação. Uma vez que toca as pessoas, a guerra as acompanha para onde quer que elas fujam. Portanto o trauma, o medo, as feridas da guerra sempre vazam, sempre alcançam os espaços de refúgio, impregnando-os de rastros do conflito. "Minha única posse era o medo" (COUTO, 2015, p. 100), conta Kindzu, personagem e também um dos narradores do livro, por meio de seu diário. "Sim, foi para escapar do medo que saíra de minha pequena vila. Porque esse sentimento já totalmente me ocupava: eu passeava com o medo na rua, dormia com o medo em casa" (COUTO, 2015, p. 100).

Essa e outras confissões chegam a nossos olhos sempre que o garoto Muidinga lê os diários de Kindzu, cadernos que ele encontrou junto ao corpo de um homem enquanto sonambulava por uma das estradas que a guerra matou em companhia do velho Tuahir. $\mathrm{O}$ ancião e a criança não são parentes de sangue, salvo se considerarmos que os laços criados na sanguinolência da guerra também sejam vínculos de sangue. Tuahir encontra um garoto moribundo e desmemoriado em um campo de refugiados e se empenha em salvá-lo. Em seguida tomam a estrada, sem destino certo. Pelo menos até encontrarem os cadernos de Kindzu, quando saber o que acontece no relato daquele estranho passa a ser tão importante quanto seguir caminhando; por vezes, mais importante do que caminhar, como quando Tuahir está à beira da morte por envenenamento alimentar e, em vez de pedir a Muidinga que vá atrás de ajuda, pede à criança que leia para ele. Além do mais, é só depois que apanham os cadernos que o velho e o menino percebem que a estrada onde estão tem algo de mágico: ela anda sozinha, fazendo com que as distâncias e paisagens do futuro sejam imprevisíveis. Temos aqui nítida ilustração da ideia de Bhabha (1992), de que a produção de significados e de valores é um "ato de sobrevivência cultural", a "colocação de uma 'aura' de individualidade na rotina alienadora, uma promessa de prazer" (BHABHA, 1992, p. 47, tradução nossa²). Em outras palavras, Bhabha (1992) entende a cultura como condição de sobrevivência, e em Terra sonâmbula essa ideia é metonimizada em se mostrando a relevância que a literatura adquire para Tuahir e para Muidinga, que dela usufruem em seu périplo descaminhado, bem como para Kindzu, o autor das histórias que os outros dois leem.

Kindzu é um jovem aldeão do sul de Moçambique. Mesmo contrariando a vontade dos pais, ele ruma para o norte do país a fim de encontrar os misteriosos naparamas, "guerreiros tradicionais, abençoados pelos feiticeiros, que lutavam contra os fazedores de guerra. [...] Combatiam com lanças, zagaias, arcos. Nenhum tiro lhes incomodava, eles

2 No trecho original, a cultura é definida como "[...] an uneven, incomplete production of meaning and

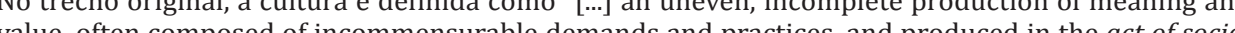
survival Culture reaches out to create a symbolic textuality to give the aljenting everyday an 'aur' of selfhood, a promise of pleasure." (BHABHA, 1992, p. 47, grifos nossos). 
estavam blindados, protegidos contra balas" (COUTO, 2015, p. 25). ${ }^{3}$ Há desejo mais tentador, para quem vive o medo da guerra, do que o corpo fechado? Talvez o amor, somente. Porque a busca de Kindzu pelos naparamas se interrompe justo quando, dentro de um barco encalhado e abandonado no meio do mar, ele encontra Farida, autoexilada nas entranhas daquela ilha artificial porque sentia que "em terra ela já não tinha nenhum lugar" (COUTO, 2015, p. 80). Farida é vítima de estupro de um colono português, mãe de um bebê nascido desse crime e o qual ela abandonou, anos depois se arrependendo de tê-lo feito, mas então já era tarde demais: a criança, chamada Gaspar, havia fugido do orfanato onde crescera. "Por motivo dessa criança, ela só chorava lágrimas de leite” (COUTO, 2015, p. 80) e sentia o corpo semelhante ao da luz de um farol, "acendendo e apagando tal igual a minha vontade de viver" (COUTO, 2015, p. 81). Por amor a Farida ou por compaixão ao amor de Farida pelo filho perdido, Kindzu decide que encontrar o garoto é missão mais urgente do que se juntar aos naparamas, mas no fim das contas não terá êxito em nenhuma das tarefas e, ao que tudo indica, elas o levarão à morte.

Traço comum de muitas histórias de Mia Couto, a trama se envereda por caminhos cujas saídas só se encontram no âmbito da palavra. Nas últimas páginas de Terra sonâmbula, Kindzu não encontra Gaspar e ainda por cima descobre que Farida morreu em um acidente ao tentar reativar um velho farol, alegoria de sua própria vontade de viver. Cansado de todos

${ }^{3}$ A título de curiosidade, efetivamente existiram os naparamas, espécie de milícia paramilitar surgida nas camadas populares e que supostamente não estava aliada a nenhum dos lados do conflito, antes combatendo a própria guerra e seus representantes. E não foi somente em Moçambique que esse tipo de agrupamento surgiu. Denov (2010, p. 68-69) nos conta que, na Guerra Civil de Serra Leoa (1991-2002), apareceram os kamajors ('caçadores', na língua mende), guerreiros reverenciados por seu misticismo e que alegadamente eram dotados de superpoderes, como o de ter o corpo blindado contra balas. Mas, enquanto Couto (2015), em seu romance, segue o tratamento de reverência, no caso que eles, como as principais forças em conflito, também cometeram abusos e crimes de guerra. os seus fracassos, desejoso de "me emigrar deste corpo cheio de esperas e sofrências" (COUTO, 2015, p. 192), Kindzu decide parar de escrever, reservando seu último esforço de escrita a contar um sonho. Nesse sonho ele assiste a um feiticeiro proclamar um discurso apocalíptico para uma multidão de miseráveis e logo em seguida o bruxo transforma todos em animais. Também a sua família ele encontra no sonho, mas se despede dela porque é movido por uma ânsia de tomar a estrada. Nessa caminhada, em algum momento, Kindzu sente um baque na cabeça, vem-lhe a dor, a vontade de desfalecer, fazendo com que largue a sacola com seus diários, mas ainda assim continua a andar e, adiante, encontra um garoto com seus próprios cadernos, um menino que ele reconhece como Gaspar. Os dois tempos da narrativa finalmente se encontram: Kindzu é mesmo o homem morto que Muidinga ou Gaspar encontra junto dos cadernos, e Muidinga é personagem do sonho de um Kindzu ainda vivo. E nada disso soa absurdo, porque, ao longo da narrativa, somos informados de que "[u]ma coisa a guerra faz acontecer: tudo vai se tornando verdade. Está-se pisando a fronteira, morte e vida nos trocáveis lados de um mesmo risco" (COUTO, 2015, p. 78). Por isso Kindzu consegue se fazer ouvir quando grita em seu sonho: Gaspar!

E o menino estremece como se nascesse por uma segunda vez. De sua mão tombam os cadernos. Movidas por um vento que nascia não do ar mas do próprio chão, as folhas se espalham pela estrada. Então, as letras, uma por uma, se vão convertendo em grãos de areia e, aos poucos, todos meus escritos se vão transformando em páginas da terra (COUTO, 2015, p. 197)

Essa cena final, tão bonita, é que faz com que eu repita que, nas histórias de Mia Couto, a trama por vezes não se resolve na ação dos personagens, e sim na performance da linguagem, "reinvestindo na palavra o mágico reinício de tudo" (COUTO, 2005, p. 224). Vale para Terra sonâmbula (e outras narrativas do autor) o mesmo que Foucault (1999) disse para Dom 
Quixote: "aí a linguagem rompe seu velho parentesco com as coisas, para entrar nessa soberania solitária onde só reaparecerá, em seu ser absoluto, tornada literatura" (FOUCAULT, 1999, p. 67).

Para Foucault (1999), Dom Quixote marcou a entrada da semelhança na "idade [...] da desrazão e da imaginação" (FOUCAULT, 1999, p. 67), e essa nova era da representação trouxe à cena dois personagens que se destacam justamente por presentificarem até hoje o desligamento entre os signos e a similitude: são eles o poeta e o louco. Curiosamente, ambos estão presentes em Terra sonâmbula, e é deles que eu quero tratar a seguir.

\section{Trecho B: o poeta e o louco}

Foucault (1999) nos diz que o louco, "entendido não como doente, mas como desvio constituído e mantido, [...] tornou-se, na experiência ocidental, o homem das semelhanças selvagens" (FOUCAULT, 1999, p. 67). É o sujeito "que se alienou na analogia" (FOUCAULT, 1999, p. 67). Como "por toda a parte vê semelhanças e sinais de semelhança; todos os signos para ele se assemelham e todas as semelhanças valem como signos" (FOUCAULT, 1999, p. 67), o louco "crê desmascarar e impõe uma máscara" (FOUCAULT, 1999, p. 67), uma nova camada de significação, cuja semiose pode nos colocar diante do abismo inescrutável do real, se consegue fazer com que tensionemos a naturalidade entre significado e significante. $O$ discurso do louco - de quem é considerado louco - rompe um dos enquadramentos mais caros à sociedade ocidental: aquele que pensa a linguagem como conjuração da essência divina das coisas. Mas o atributo que permite ao louco fazer esse rompimento não é exclusivo dele. Com efeito, está disponível a todos que jogam o jogo da linguagem - para usar uma analogia cara a Saussure (2006) -, a todos nós. É isso que, a meu ver, defende Butler (2015) quando afirma que o ato de enquadrar os signos, isto é, de contê-los em determinado contexto de significação, só funciona se esse contexto puder ser moldado, adaptado, e é isso que, em última instância, permite que se mude tanto o contexto, que ele vire outra coisa, destruindo o próprio enquadramento que se desejava difundir. É disso também que, a meu ver, trata Bhabha (1992) quando afirma que a tradutibilidade, a capacidade de se traduzirem culturalmente, é uma característica de sobrevivência dos signos. E é ainda o que, creio eu, pensa Derrida $(1973,1995,2005)$ ao apregoar que a desconstrução sempre parte da própria estrutura com que foram construídas as significações reificadas. Portanto, em que pesem disposições distintas, o tabuleiro que o louco bagunça outros também podem bagunçar. Por isso Foucault (1999) traz o poeta como a contraface do louco.

[0] poeta é aquele que, por sob as diferenças nomeadas e cotidianamente previstas, reencontra os parentescos subterrâneos das coisas, suas similitudes dispersadas. Sob os signos estabelecidos e apesar deles, ouve um outro discurso, mais profundo, que lembra o tempo em que as palavras cintilavam na semelhança universal das coisas (FOUCAULT, 1999, p. 67-68).

O poeta seria o sacerdote do templo onde a linguagem é o que nos conecta a Deus, dessa crença que Derrida (1973) chamou de 'metafísica da presença'. Os (des)mascaramentos, os tensionamentos realizados pelo poeta não são vistos como baderna, nem como gratuita vontade de caos, muito menos como danação da alma ou, pior, da racionalidade. São antes tidos como o que de melhor o espírito humano pode produzir.

Mas o que faz com que o poeta seja louvado, e o louco, chutado? Certamente não é algo dado pela linguagem, uma vez que concluímos que ambos se valem do mesmo jogo, do mesmo tabuleiro. Foucault (1996) nos dá pistas de que essa chancela vem de fora, vem das disputas sociais, materializadas em instituições e mecanismos de controle do discurso. A chaça de poeta ou de louco, em alguma medida, independe do modo como 
se usa a linguagem; está relacionada sobretudo ao modo como é visto esse uso, em se considerando o status social do sujeito enunciador. ${ }^{4}$

O poeta e o louco se fazem presentes em Terra sonâmbula e, curiosamente, a distinção social denunciada por Foucault (1999), também. Afinal, conhecemos a história por meio dos diários de Kindzu, e ainda que sua história, para terminar, tenha de tensionar a linguagem até ferir o tempo inesperadamente, ou seguimos com ele, compactuamos, ou fechamos o livro. $O$ poeta do gênero romance nos seduz estimulando o desejo de saber, o velho desejo que fez Adão e Eva morderem o fruto proibido e fez Odin agonizar por nove dias pendurado em uma árvore. Quem deseja algo tem uma fraqueza que pode ser explorada. Se esse desejo é o de saber, a fraqueza é ainda maior, pois a medida de sua satisfação é imensurável $a$ priori. Por isso o narrador-personagem, o poeta de Terra sonâmbula, pode nos lançar ao caos de seu inconsciente. Aceitamos de bom grado sua justificativa de que, "[n]aquele território, tão despido de brilho, ter razão é algo que já não dá vontade" (COUTO, 2015, p. 10). A promessa do gozo de saber é o minadouro da nossa tolerância para com ele.

Quanto ao louco - melhor dizendo, a louca - de Terra sonâmbula, seu nome é Virgínia. Dona Virgínia Pinto, uma senhora portuguesa, esposa do colono que estuprou Farida, o falecido pai de Gaspar ou Muidinga, cujo fantasma continua neste plano, a tramar maldades e maracutaias junto com o corrupto administrador da cidadezinha onde moram. De dona Virgínia se diz que ela

amealha fantasias, cada vez mais se infanciando. Suas únicas visitas são essas crianças que, desde a mais tenra manhã, enchem o som de muitas

\footnotetext{
${ }_{4}^{4}$ Também com base no Dom Quixote, Jauss (1994, p. 27-30) argumenta que o êxito literário - condição para se alcançar e se manter o status de escritor ou de poeta - demanda que se negocie o tempo inteiro com um horizonte de expectativas do leitor, o que implica num tipo de autocontenção cujo desrespeito pode ser tomado justo como uma das características atribuídas ao louco.
}

cores. Os pais dos meninos aplicam bondades na velha, trazem-lhe comida bons-cumprimentos. A vida finge, a velha faz conta. No final, as duas se escapam, fugidias, ela e a vida. (COUTO, 2015, p. 154)

Essas são palavras de Kindzu, que vai ter com a velha ao saber das ligações de Farida com sua família e, para sua surpresa, descobre que Virgínia deliberadamente tomara para si o papel de louca como estratégia de autopreservação, até mesmo em relação ao fantasma de Romão, seu marido vigarista. Quando Kindzu pede para acompanhá-la enquanto ela alimenta seus sapos de estimação, Virgínia declara que não quer que os vejam juntos. “E porquê??" (COUTO, 2015, p. 165), indaga o rapaz.

- Não esqueça eu sou uma velha tonta, não falo com gente crescida. Só mereço confiança das crianças. Sabe o que ando a adivinhar? Que o Romão quer que eu assine papéis autorizando dinheiros. Como é que posso assinar um papel? E dinheiro, eu sei o que é dinheiro? Não faço nenhuma ideia. Me entende, Kindzu? (COUTO, 2015, p. 165, grifos do autor).

O meio sorriso que essa declaração pode vir a provocar evidencia que reconhecemos o enquadramento da condição precária do louco, mas, ao mesmo tempo, essa precariedade é ressignificada - o enquadramento é trincado - quando nos damos conta de que a loucura está sendo utilizada como tática de sobrevivência. É a loucura, afinal, que garante que Virgínia, mulher e colona, mantenha o espólio do casamento integralmente, receba comida e atenção e não precise se envolver na bagunça da guerra, a perigosa bagunça que leva um personagem a afirmar que, em Moçambique, "a guerra gerava altos tacos [dinheiros], cada um semeava uma guerra particular. Cada um punha as vidas dos outros a render" (COUTO, 2015, p. 126). Nesse contexto, é sagaz a estratégia de autopreservação de dona Virgínia. Remete a Certeau (1998), quando este afirma que "[o] cotidiano se inventa com mil maneiras de caça não autorizada" (CERTEAU, 1998, p. 38), inclusive em âmbito simbólico. 
Certeau (1998) nos atenta a que "[a] presença e a circulação de uma representação [...] não indicam de modo algum o que ela é para seus usuários" (CERTEAU, 1998, p. 40). No que diz respeito à linguagem, Certeau (1998) nos recorda de que, em linguística, performance não é sinônimo de competência: "o ato de falar [...] não pode ser reduzido ao conhecimento da língua" (CERTEAU, 1998, p. 40). Deve-se antes considerar que esse ato "coloca em jogo uma apropriação, ou uma reapropriação, da língua por locutores; instaura um presente relativo a um momento e a um lugar; e estabelece um contrato com o outro (o interlocutor) numa rede de lugares e de relações" (CERTEAU, 1998, p. 40). Em se considerando tudo isso, percebemos que dona Virgínia se apropria do discurso atribuído ao louco para tomar para si um enquadramento que, de fato, se transformara em refúgio. No contexto da guerra, quando se mina a estabilidade do regime de precariedade das diferentes vidas - isto é, quando a ordem das vidas que valem mais dentro de determinado grupo social começa a mudar, por conta dos câmbios de enquadramento engendrados pelo conflito -, a velha percebe que o mais seguro é ser louca. Com dona Virgínia, a invisibilidade do louco deixa de causar pena. É, com efeito, a maneira mais inteligente de lidar com a guerra, entre todas as que a história traz. Digo isso porque, em suas aparições, no romance, dona Virgínia nunca está se lamentando.

\section{Trecho C: a criança}

Neste trecho de nosso mapa de fugas, constato algo que parece ter escapado a Foucault (1999): o fato de que a criança é o parceiro número três nos jogos de bagunçar a linguagem que praticam o poeta e o louco. Os três são companheiros de brincriações, e Terra sonâmbula mostra essa conexão ao fazer das crianças os principais interlocutores do poeta e do louco. É o caso de Muidinga, quem encontra os cadernos de Kindzu e quem, ao final do romance, consegue escutá-lo desde as linhas do sonho narrado pelo próprio Kindzu. E é também o caso das crianças que cercam dona Virgínia todos os dias, pedindo à vavó que lhes conte alguma história. Sucede que, nessas rodas de contação, não raro,

[n]o enquanto da estória, o dito avô ia perdendo o nome, saltitando de morada e profissão. Os meninos, por vezes, corrigiam: o mucunha Curucho, não esqueça vavó. Mais Virgínia repete os contos mais a verdade se resvala: o avô Cruz de olhos louros, hoje; amanhã um negro de rosto carapinhoso. A criançada nem se importa. Verdade, em infância, é um jogo de brincar (COUTO, 2015, p. 156).

Esse desinteresse pela verdade, que no poeta é rito de criação e no louco, pobre danação, funciona também como justificativa da teleologia da infância, um processo de subalternização que se dá sob o mito condescendente da inocência, da ignorância, do despreparo para a vida. Como nos conta Postman (1999), o regime de verdade em torno da infância começou a ser construído no princípio do mundo pós-Gutenberg.

O que aconteceu, simplesmente, foi que o Homem Letrado tinha sido criado. E ao chegar, deixou para trás as crianças. Pois, no mundo medieval, nem os jovens nem os velhos sabiam ler e seu interesse era o aqui e agora, o "imediato e local" [...]. É por isso que não havia necessidade da ideia de infância, porque todos compartilhavam o mesmo ambiente informacional e, portanto, viviam no mesmo mundo social e intelectual. Mas, quando a prensa tipográfica fez sua jogada, tornou-se evidente que uma nova espécie de idade adulta tinha sido inventada. A partir daí a idade adulta tinha de ser conquistada. Tornou-se uma realização simbólica e não biológica. (POSTMAN, 1999, p. 50)

Para além de Terra sonâmbula, outros textos, como Precisamos falar sobre o Kevin, romance de Lionel Shriver (2007), ou o documentário A ira de um anjo (1990), produzido pela HBO, nos permitem observar ou questionar a temática da inocência do discurso infantil e, consequentemente, reiteram 
a ideia aqui defendida, de que, como o louco e o poeta, também a criança está "na orla exterior da nossa cultura e na proximidade maior de suas divisões essenciais" (FOUCAULT, 1999, p. 68), em uma "situação de 'limite' [...] onde suas palavras encontram incessantemente seu poder de estranheza e o recurso de sua contestação" (FOUCAULT, 1999, p. 68). De sobreaviso pelo caso de dona Virgínia, é válido mencionar que essa marginalização da infância não é uma condenação indelével. Bem pode ser um enquadramento vantajoso. Em Terra sonâmbula, as crianças que acompanham a louca desfrutam dos mesmos cuidados e distanciamentos da guerra de que ela goza - ela, quem, em sua loucura, diz o narrador, se está infanciando. Em Precisamos falar sobre o Kevin, um garoto psicopata consegue se safar de suas vilanias ao longo de toda a infância, desestabilizando o emocional de sua mãe, que se questiona o tempo inteiro se ela não está cometendo o vitupério de vê-lo com maus olhos, mal interpretando seu comportamento, afinal se trata de uma criança! O mesmo pensamento temos nós quando, em $A$ ira de um anjo, vemos os registros psiquiátricos de Beth Thomas, vídeos nos quais a garotinha conta com voz cândida seus desejos assassinos direcionados aos bichinhos de estimação e aos familiares, em especial ao irmãozinho caçula. Já no documentário $O$ impostor (2012), que conta a história do famoso vigarista francês, Frédéric Bourdin, ouvimos como ele, aos 23 anos, conseguiu se passar por um adolescente de cerca de 15 anos somente por ter consciência dos elementos que compõem o enquadramento dos não adultos, sobretudo elementos de medo e fragilidade.

Estima-se que Bourdin, apelidado de 0 Camaleão, tenha assumido mais de 500 identidades, a mais famosa delas sendo a do adolescente de 15/23 anos. No decorrer dessa história, que mais parece ficção, Frédéric Bourdin tomou para si a identidade de Nicholas Barclay, um garoto texano que havia desaparecido três anos antes. Bourdin então convenceu muita gente de que era mesmo esse menino, inclusive a própria família de Nicholas, com quem morou por um tempo. Tudo isso, apesar de seu sotaque francês e apesar de ter olhos castanhos, quando o verdadeiro Nicholas tinha olhos azuis. Mas quem ousaria duvidar em voz alta de um menino assustado, perceptivelmente traumatizado?

Kevin, Beth e Frédéric/Nicholas nos dão pistas de que aceitar o limitante enquadramento da infância também pode ser uma estratégia de autopreservação. Por vezes, é a única proteção que temos contra sermos enquadrados pelo direito penal.

\section{$5 \quad$ Nosso último trecho juntos}

Refletindo sobre o discurso da criança, Deleuze (1997) nos oferece uma perspectiva positiva das brincriações que, agora sabemos, não só a criança gosta de fazer. Escreve ele que “[o] próprio da libido é impregnar a história e a geografia, organizar formações de mundos e constelações de universos, derivar os continentes, povoá-los com raças, tribos e nações" (DELEUZE, 1997, p. 74). E complementa:

A libido não tem metamorfoses, mas trajetórias histórico-mundiais. Desse ponto de vista, não parece que o real e o imaginário formem uma distinção pertinente. Uma viagem real carece em si mesma de força para refletir-se na imaginação; e a viagem imaginária não tem em si mesma a força, como diz Proust, de se verificar no real. Por isso o imaginário e o real devem ser antes como que duas partes, que se pode justapor ou superpor, de uma mesma trajetória, duas faces que não param de intercambiar-se [...]. (DELEUZE, 1997, p. 74-75)

Entendendo a libido como "pulsão de vida" (ROUDINESCO; PLON, 1998, p. 472), como o "que mantém a coesão de tudo aquilo que vive" (ROUDINESCO; PLON, 1998, p. 474), esse conceito parece se aproximar 
da noção de cultura como sobrevivência, defendida por Bhabha (1992): a ideia de que, para continuarmos vivos, é fundamental a "colocação de uma 'aura' de individualidade na rotina alienadora, uma promessa de prazer" (BHABHA, 1992, p. 47; tradução nossa ${ }^{5}$ ) que se dá justamente pela produção de significados e de valores no cotidiano. Nesse contexto, a brincriação se mostra como uma manifestação da libido e nos faz suspeitar de que a vontade de bagunçar o tabuleiro do jogo da língua seja uma necessidade vital, ainda que pontual, do eu. Por isso mesmo, a consideração última a ser feita é a de que, mesmo fora do caos da guerra, mesmo quando brincar com os signos não é uma estratégia com vistas a que sejamos enquadrados em uma posição social que sirva de proteção, há momentos de nossa "rotina alienadora", de "viagem real", em que precisamos nos fazer de loucos, de poetas ou de crianças.

E nem é preciso que cada um eleja entre esses enquadramentos aquele que mais se afina à sua personalidade. Não é preciso fazer escolhas exclusivas. Quando confrontamos as habilidades camaleônicas de Bourdin no caso Barclay com o teatro de dona Virgínia em Terra sonâmbula, percebemos que esses dois sujeitos não estão tão distantes um do outro. Em ambos os casos, foram necessários, no mínimo, uma magistral capacidade narrativa e performática, bem como um desligamento quase completo da ética do senso comum. Sendo assim, o homem que se passa por um adolescente amedrontado e a velha que finge caducar uma volta à infância nos mostram que por vezes o poeta, o louco e a criança podem habitar concomitantemente uma mesma pessoa.

\footnotetext{
${ }^{5}$ Cf. nota de rodapé no 2 .
}

\section{Referências}

A IRA de um anjo: a história de um abuso. Produção: Gaby Monet Jacoby, Dalton Delan. Edição: Arthur Ginsberg. Narração: Joel Graiger. Com: Ken Magid, Beth Thomas e outros. [S.I.]: HBO. 1990. 1 arquivo digital (28 min.), son., color. Disponível em: <https://youtu. be/8Bp-cgUQpbk>. Acesso em: 3 set. 2017.

ARAGÃO, Fernanda Maria Baraúna de Freitas. Vozes de Nacala: uma análise sobre as potencialidades e limites da articulação contra o ProSAVANA. 2017. 238 fls. Dissertação (Mestrado em Relações Internacionais) - Universidade Federal da Bahia, Salvador, 2017.

BHABHA, Homi K. Freedom's basis in the indeterminate. October, v. 61, p. 45-67, 1992. Disponível em: <http://www.jstor.org/stable/778784>. Acesso em 4 set. 2014.

BUTLER, Judith. Introdução: vida precária, vida passível de luto. In: BUTLER, Judith. Quadros de guerra: quando a vida é passível de luto? Trad. Sérgio Tadeu de Niemeyer Lamarão e Arnaldo Marques da Cunha, revisão Marina Vargas e revisão técnica Carla Rodrigues. Rio de Janeiro: Civilização Brasileira, 2015. p. 13-55.

CERTEAU, Michel de. A invenção do cotidiano: artes de fazer. Trad. Ephraim Ferreira Alves. 3. ed. Petrópolis: Vozes, 1998.

COUTO, Mia. Palavras proferidas por Mia Couto na entrega do Prémio Mário António, da Fundação Calouste Gulbenkian, em 12 de junho de 2001. In: COUTO, Mia. $O$ último voo do flamingo. São Paulo: Companhia das Letras, 2005. p. 223-225.

COUTO, Mia. Terra sonâmbula. São Paulo: Companhia de Bolso, 2015.

DELEUZE, Gilles. O que as crianças dizem. In: DELEUZE, Gilles. Crítica e clínica. Trad. Peter Pál Pelbart. São Paulo: 34, 1997. p. 73-79.

DENOV, Myriam. Recipe for rebellion: civil war in Sierra Leone. In: DENOV, Myriam. Child soldiers: Sierra Leone's Revolutionary United Front. Cambridge: Cambridge University Press, 2010. p. 48-79.

DERRIDA, Jacques. Gramatologia. Trad. Miriam Schnaiderman e Renato Janini Ribeiro. São Paulo: Perspectiva, Ed. da Universidade de São Paulo, 1973.

DERRIDA, Jacques. A Estrutura, o signo e o jogo no discurso das ciências humanas. In: DERRIDA, Jacques. A escritura e a diferença. Trad. Maria Beatriz Marques Nizza da Silva, revisão Mary Amazonas Leite de Barros e produção Ricardo W. Neves e Adriana Garcia. 2. ed. São Paulo: Perspectiva, 1995. p. 227-248. 
DERRIDA, Jacques. Kólaphos/Kolápto. In: DERRIDA, Jacques. A farmácia de Platão. Trad. Rogério Costa. 3. ed. São Paulo: Iluminuras, 2005. p. 7-10.

FOUCAULT, Michel. A ordem do discurso. Aula inaugural no Collège de France, pronunciada em 2 de dezembro de 1970. Trad. Laura Fraga de Almeida Sampaio. 5. ed. São Paulo: Edições Loyola, 1996.

FOUCAULT, Michel. Representar. In: FOUCAULT, Michel. As palavras e as coisas: uma arqueologia das ciências humanas. Trad. Salma Tannus Muchail. 8. ed. São Paulo: Martins Fontes, 1999. p. 63-106.

JAUSS, Hans Robert. A história da literatura como provocação à teoria literária. Trad. Sérgio Tellaroli. São Paulo: Ática, 1994.

O IMPOSTOR. Direção: Bart Layton. Produção: John Battsek, Sam Brown, Katherine Butler, Simon Chinn, Paul Cziok, Robert DeBitetto, Poppy Dixon, Dimitri Goanis, John Farrar, Kate Horne, Tabitha Jackson, Paloma López Vázquez, Mary-Jane Mitchell, Randy Murray, Theresa Murray, Rob Sharenow, Molly Thompson e Vanessa Tovell. Com: Frédéric Bourdin, Carey Gibson, Bryan Gibson, Beverly Dollarhide, Nancy Fisher e outros. [S.I.]: Indomina, A\&E IndieFilms. 2012. 1 arquivo digital (99 min.), son., color.

POSTMAN, Neil. O desaparecimento da infância. Trad. Suzana M. de Alencar Carvalho e José Laurentino de Melo. Rio de Janeiro: Grafhia, 1999.

ROUDINESCO, Elisabeth; PLON, Michel. Dicionário de psicanálise. Trad. Vera Ribeiro e Lucy Magalhães, supervisão Marco Antonio Coutinho Jorge. Rio de Janeiro: Zahar, 1998. p. 471-474.

SAUSSURE, Ferdinand de. Curso de linguística geral. Org. Charles Bally e Albert Sechehaye, colaboração Albert Riedlinger. Trad. Antônio Chelini, José Paulo Paes e Izidoro Blikstein. 27. ed. São Paulo: Cultrix, 2006.

SHRIVER, Lionel. Precisamos falar sobre o Kevin. Trad. Beth Vieira e Vera Ribeiro. Rio de Janeiro: Intrínseca, 2007.

Recebido em 14/09/2017.

Aceito em 20/01/2018 